\title{
Bone-patellar Tendon-bone Versus Four Strands Hamstring Grafts for Anterior Cruciate Ligament Reconstruction
}

\author{
F. Migliorini ${ }^{1}$, J. Eschweiler ${ }^{2}$, M. Tingart ${ }^{3}$, M. Niewiera ${ }^{3}$, B. Rath ${ }^{2}$ \\ 1 Universitatsklinikum Aachen, Aachen, Germany \\ 2 Department of Orthopaedic, University Clinic Aachen, RWTH Aachen University Clinic, Aachen, Germany \\ 3 Department of General Surgery, Eifelklinik St. Brigida, Simmerath, Germany
}

\section{CORRESPONDING AUTHOR: \\ Filippo Migliorini \\ Universitatsklinikum Aachen \\ Pauwelsstraße 30, 52074 \\ Aachen, Germany \\ E-mail: migliorini.md@gmail.com}

DOI:

10.32098/mltj.01.2020.09

LEVEL OF EVIDENCE: 1

\begin{abstract}
SUMMARY
Introduction. The goal of the present meta-analysis was to compare bone-patellar tendon-bone (BPTB) versus four-strands hamstring tendon (4SHT) autografts for primary anterior cruciate ligament (ACL) reconstruction.

Methods. The present meta-analysis was conducted according to the PRISMA guidelines. The literature search was performed in July 2019. All the randomized clinical trials comparing BPTB versus 4SHT autografts for primary ACL reconstruction were considered for inclusion. The statistical analysis was performed through the Review Manager Software.

Results. The BPTB detected lower values of pivot-shift test $\geq 3 \mathrm{~mm}(\mathrm{p}=0.0009)$, Lachman test $\geq 5 \mathrm{~mm}(\mathrm{p}=0.03)$, arthrometer displacement $\geq 3 \mathrm{~mm}(\mathrm{p}=0.001)$, mean arthrometer displacement $(\mathrm{p}=0.50)$, higher rate of kneeling pain $(\mathrm{p}=0.01)$, anterior knee pain $(\mathrm{p}<0.0001)$ and graft failures $(\mathrm{p}=0.03)$. Concerning the clinical scores (IKCD and Lysholm score), any statistically significant results were detected.

Conclusions. Providing more stability, we hypothesize that young and demanding patients may gain more benefits from BPTB graft. In the case of treating patients with reduced performances, it may be more reasonable to use a 4SHT because of the lower incidence of graft rupture, kneeling, and anterior knee pain.
\end{abstract}

KEY WORDS

ACL reconstruction four strands bamstring tendon; bone-patellar tendon-bone tendon; autograft

\section{INTRODUCTION}

The anterior cruciate ligament (ACL) is one of the most important stabilisers of the knee. It prevents the antero-posterior sliding of the tibia against the femur, along with excessive knee extension, tibial rotation, and varus-valgus movements $(1,2)$. Sudden decelerations combined with directional change and landing with nearly full extended knee after a jump are the most common causes of ACL injury (3). A direct trauma causing a posterior translation of the tibia in respect to the femur is another cause, but very uncommon (4). Short-term complications of the ACL rupture are represented by soft tissue damages (5) along with joint instability (6). The most important long-term complication is represented by the osteoarthritis $(7,8)$. These complications lead to a poor quality of life and to a reduction of the recreation- al activities $(9,10)$. A timely intervention is of paramount importance to restore the normal joint biomechanics and avoid additional complications. The most used grafts for ACL reconstruction are the bone-patellar tendon-bone (BPTB) and the four strands hamstring tendon (4SHT) autografts. Despite the huge number of clinical trials, there are still controversial opinions concerning which one is the best choice for ACL reconstruction (11-17). In the literature, many randomized clinical trials $(\mathrm{RCTs})$ and prospective studies compare the two grafts $(13,18-21)$. In the last years, the number of studies comparing the two grafts has remarkably improved $(16,17)$. The purpose of this work is to review the current literature and to summarize and update the current evidences concerning BTPB versus 4SHT for primary ACL reconstruction. 


\section{MATERIAL AND METHODS}

\section{Search strategy}

The literature search was conducted according to the Preferred Reporting Items for Systematic Reviews and Meta-Analyses (PRISMA) guidelines (22). To guide the search, we preliminary drafted a protocol:

- type of study: clinical trials (level of evidence I or II (23));

- patient Group: tear of the anterior cruciate ligament;

- intervention: anterior cruciate ligament reconstruction;

- comparison: bone-patellar tendon-bone graft versus four strands hamstring tendon;

- outcomes: joint laxity, clinical scores, further complications.

We used the following keywords for the literature search: ACL, rupture, reconstruction, hamstring, B-PT-B, autograft, pivot-shift, Lachman, laxity, arthrometer, IKDC, Lysholm, failures, anterior knee pain, kneeling, revisions. Disagreements between the authors were debated and mutually solved.

\section{Data extraction and eligibility criteria}

Two independent authors (FM, BR) performed the data extraction. All the published study comparing bone-patellar tendon-bone versus four strands hamstring tendon for ACL reconstruction were considered for inclusion. According to the Oxford Center of Evidenced-Based Medicine (23), articles level of evidence I to II were enrolled in the present study. Retrospective cohort studies, case series, editorials, expert opinions or other reviews were excluded from the present work. Biomechanical, cadaveric, animal and in-vitro studies were rejected. Studies providing navigation system or robotic surgery, along with revision setting were excluded. Studies concerning 2 or 6 strands hamstring tendon were not considered. Studies performing the surgeries with synthetic grafts, allografts or xenografts were rejected. According to the authors languages capabilities, studies in English, German, Italian, Spanish, French were included. Studies published in a timeframe from 2000 to November 2018 were included. Only studies reporting quantitative data under the outcomes of interest were considered in this study. Disagreements between the authors were debated and mutually solved.

\section{OUTCOMES}

We reported the generalities of the included studies (author and publication's year, number of patients, mean age, mean follow-up). To measure the post-operative knee laxity, we referred to the Lachman and pivot-shift tests. We consid- ered pathological a displacement $\geq 5 \mathrm{~mm}$ for the Lachman test and $\geq 3 \mathrm{~mm}$ for the pivot-shift test. We included studies that measured laxity instrumentally with KT-1000, KT-2000 (MEDmetric Corp, San Diego, California) or CA-4000 (Orthopaedic System Inc, Hayward, CA, USA). These devices reproduce the sagittal translation of the tibia plateau in respect to the femur, considering pathological a displacement of $\geq 3 \mathrm{~mm}$. To assess the clinical outcome, we referred to the International Knee Documentation Committee (IKDC) and the Lysholm Knee Scoring Scale (LKSS). Further complications (kneeling pain, anterior knee pain, graft rupture) were also evaluated.

\section{Methodological quality assessment}

Two independent authors (FM, BR) evaluated the methodological quality and reliability of the included studies with the PEDro appraisal tool (24). This instrument evaluates randomization, blinding, follow-up adequacy, baseline comparability of the groups at the start, analysis for intention of treatment. Every analyzed article is then ranked from 0 (low quality) to 10 (high quality). An overall result of $\geq 6$ is considered acceptable.

\section{STATISTICAL ANALYSIS}

The statistical analysis was performed with Review Manager Software 5.3 (The Nordic Cochrane Collaboration, Copenhagen). For continuous variables, the effect estimates (EE) were evaluated with the inverse variance method. For the effect measure, the arithmetic mean was used. For dichotomous variables, the Maentel-Haenszel statistical method was used in combination with the odd ratio (OR) to evaluate the final effect. The confidence interval (CI) was fixed at $95 \%$ in all the comparisons. To analyze the heterogeneity, both ${ }^{2}$ and $\mathrm{I}^{2}$ tests were performed. Value of ${ }^{2}>0.5$ indicated heterogeneity. The $\mathrm{I}^{2}$ evaluates the heterogeneity as low $(<25 \%)$, few $(25-50 \%)$, moderate $(50-75 \%)$ and high $(>75 \%)$. A fixed analysis model was used. In front of moderate-high heterogeneity, to a random analysis method were switched. Value of $\mathrm{P}<0.05$ were considered statistically significant.

\section{RESULTS}

We obtained 356 RCTs from the database search and the cross-references screening. Of these, 112 were removed because of duplicates. Other 175 articles were rejected because they did not focus on the topic of interest. Another 49 studies were rejected because they did not analyze our outcomes of interest. This left 20 articles for the study. The flow-chart of the literature search is shown in figure $\mathbf{1 .}$ 


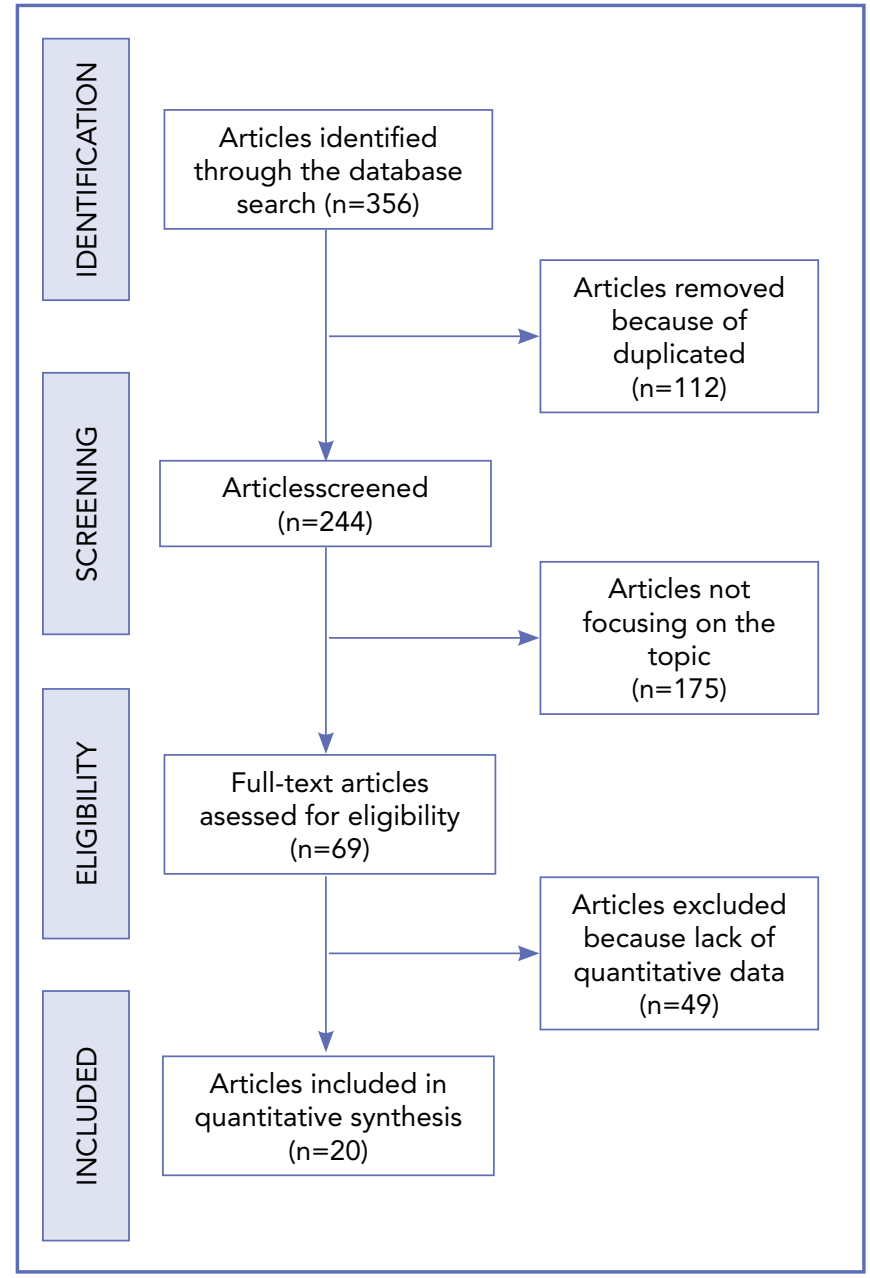

Figure 1. PRISMA flow-chart of the literature search.

\section{METHODOLOGICAL QUALITY ASSESSMENT}

The analysis of the PEDro score reported a high level of evidence and a very good analysis of the results in the included studies. All authors performed randomization in their studies and the baseline of the demographic data was comparable, representing points of strength for this meta-analysis. On the other hand, the absence of blinding methods represented an important limit of the included studies, influencing negatively the PEDro score. The overall result of the PEDro score was 7.74 points, proving the high methodological quality of this work. The results of the PEDro score are shown in table $\mathbf{I}$.

\section{ANALYSIS OF PUBLICATION'S BIAS}

To analyze the publication's bias, we performed the funnel plot of the most reported outcome (failures). All stud- ies locate in the range of acceptability and are positioned symmetrically to the non-effect line, indicating a low risk of publication's bias. The funnel plot is shown in figure 2 .

\section{PATIENT'S DEMOGRAPHICS}

We examined in this study 1651 patients that underwent a mean follow-up of $62.42 \pm 54.86$ months. We enrolled 819 patients in the BPTB group, with a mean age of $28.35 \pm 4.7$ years, and 832 patients in the 4SHT group, with a mean age of $28.3 \pm 3.59$ years. The demographic baseline is shown in table I.

\section{OUTCOMES}

Concerning the joint laxity, in the BPTB group we observed a lower number of patients with pivot-shift test $\geq 3 \mathrm{~mm}$ (OR: 0.59; CI: $0.43,0.80 ; P=0.0009)$, Lachman test $\geq 5 \mathrm{~mm}$ (OR: 0.54 ; CI: $0.31,0.94 ; P=0.03)$, and arthrometer displacement $\geq 3 \mathrm{~mm}$ (OR: 0.61; CI: $0.45,0.83 ; P=0.001$, figure 3). Moreover, in the same group we reported a reduction of the mean arthrometer displacement (EE: -0.15; CI: -0.59, 0.29; $P=0.50)$.

Concerning the clinical scores, we observed better results of the IKDC score in the BPTB group (EE: 0.72; CI: -2.28, 3.73; $P=0.64$ ) and a higher improvement of the mean Lysholm score in the 4SHT group (EE: -2.40, CI: -5.27 0.47; $P=0.10)$.

Regarding the complications, we observed a higher rate of kneeling pain (OR: 1.72; CI: $-2.28,3.73 ; P=0.014$ ) and anterior knee pain (OR: 2.84; CI: $1.75,4.61 ; P<0.0001)$ in the BPTP group. In this group, we also reported a reduction in graft failures (OR: 0.62; CI: 0.41, 0.95; $P=0.03$, figure 4). Table II summarizes the results of the meta-analysis.

\section{DISCUSSION}

The main findings of this meta-analysis are that BPTP provides more joint stability and reduced the rate of graft rupture but exposes the patients to an increased risk of developing kneeling and anterior knee pain. Giving the greater stability observed in the BPTB group, we hypothesize that young and demanding patients can get more benefits from this graft. Patients with reduced performances, it may be more reasonable to use a 4SHT because of the lower incidence of graft rupture, kneeling and anterior knee pain. Evaluating the joint stability is of fundamental importance after ACL reconstruction, since laxity lead to acute injuries (sprains, soft tissue lesions) and to long-term articular degenerative changes, such as osteoarthritis (38-40). Many different factors leading to instability have been recognized: 


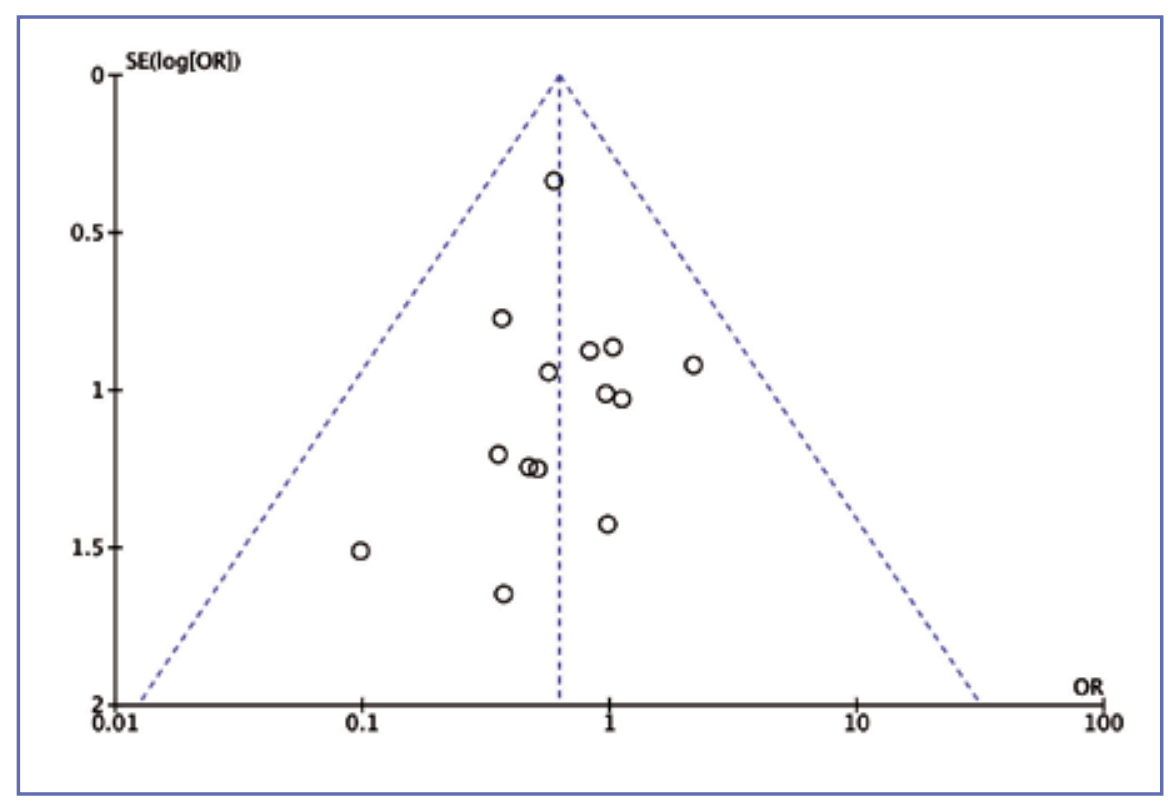

Figure 2. Funnel plot to assess the publication's bias. graft tension and knee flexion during the graft fixation, bone to bone versus bone to tendon healing, cycling of the graft (41-43). Most of enrolled studies referred to pivot-shift, Lachman test and to the arthrometer for the stability evaluation. Lachman is very sensible test, but the accuracy to detect accurate postero-anterior tibial translation is not reliable (44). Using of the arthrometer provides more reliable results and precise evaluation of the translation $(45,46)$. All the analyzed tests evidenced a better joint stability in favor of the BPTB group. These results were statistically significant across all the analyzed comparisons. The comparisons evidenced a good weights distribution, and the overall effect is affected by low level of hetero-

Table I. Baseline demographic and PEDro quality methodological assessment of the included works.

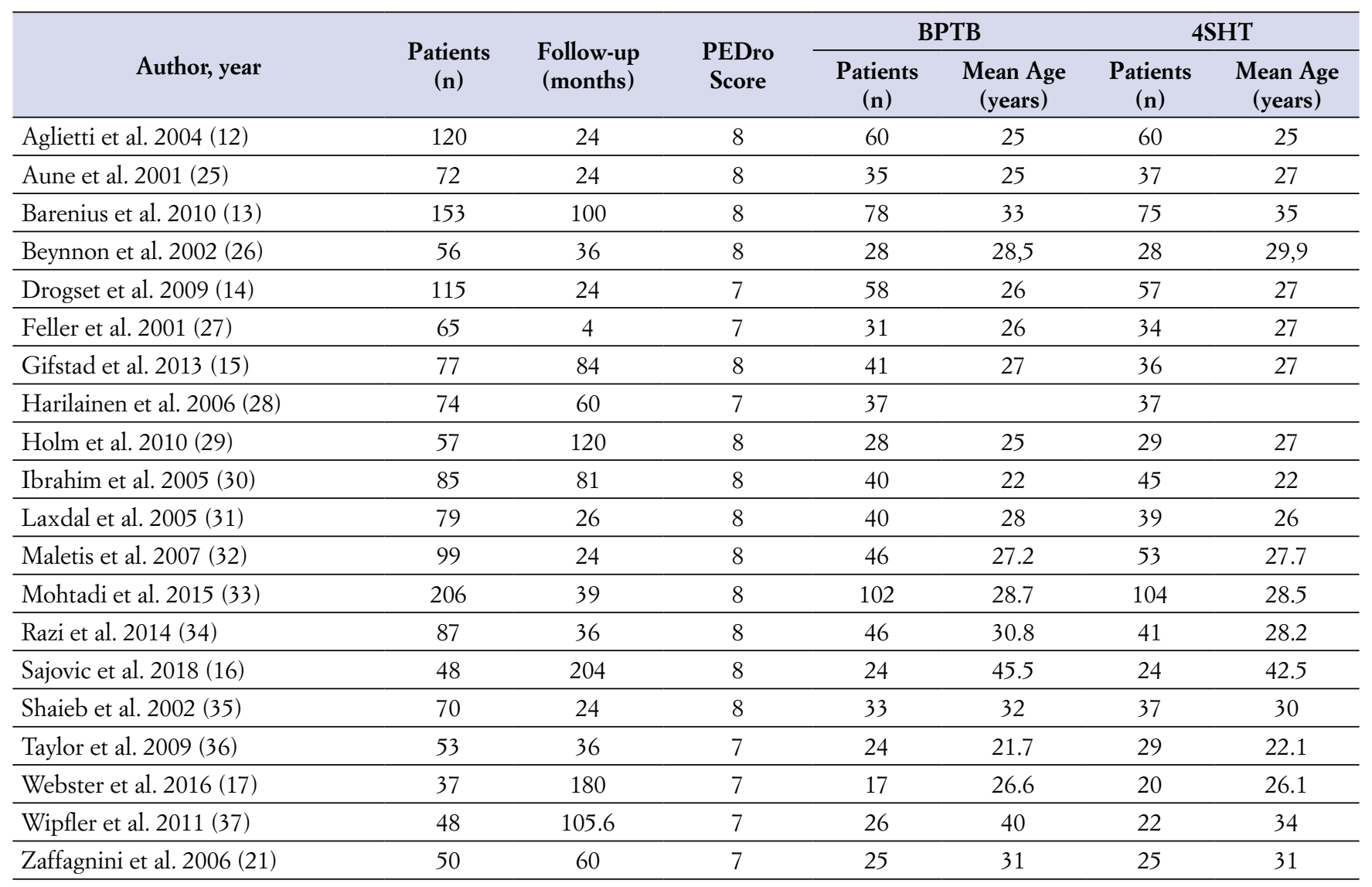




\begin{tabular}{|c|c|c|c|c|c|c|c|c|c|c|}
\hline Study or Subgroup & $\begin{array}{r}\text { PT } \\
\text { Events } \\
\end{array}$ & Total & \multicolumn{2}{|l|}{ HT } & Weight & \multirow{2}{*}{$\begin{array}{c}\begin{array}{c}\text { Odds Ratio } \\
\text { M-H, Fixed, 95\% CI }\end{array} \\
0.70[0.34,1.47]\end{array}$} & \multicolumn{4}{|c|}{$\begin{array}{c}\text { Odds Ratio } \\
\text { M-H, Fixed, } 95 \% \mathrm{Cl}\end{array}$} \\
\hline Aglietti et al. 2004 & 21 & 60 & 26 & 60 & $15.5 \%$ & & & 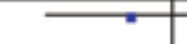 & & \\
\hline Gifstad et al. 2013 & 2 & 41 & 3 & 36 & $2.8 \%$ & $0.56[0.09,3.58]$ & & & & \\
\hline Ibrahim et al. 2005 & 5 & 40 & 7 & 45 & $5.3 \%$ & $0.78[0.23,2.67]$ & & & & \\
\hline Laxdal et al. 2005 & 6 & 40 & 7 & 39 & $5.5 \%$ & $0.81[0.24,2.66]$ & & & & \\
\hline Maletis et al. 2007 & 17 & 46 & 26 & 53 & $14.0 \%$ & $0.61[0.27,1.36]$ & & & - & \\
\hline Mohtadi et al. 2015 & 44 & 102 & 58 & 104 & $30.0 \%$ & $0.60[0.35,1.04]$ & & & & \\
\hline Sajovic et al. 2018 & 2 & 24 & 8 & 24 & $6.7 \%$ & $0.18[0.03,0.97]$ & $\leftarrow$ & & & \\
\hline Shaieb et al. 2002 & 5 & 33 & 12 & 37 & $8.8 \%$ & $0.37[0.11,1.20]$ & & & 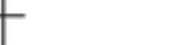 & \\
\hline Taylor et al. 2009 & 4 & 24 & 2 & 29 & $1.4 \%$ & $2.70[0.45,16.22]$ & & & & \\
\hline Webster et al. 2015 & 0 & 17 & 1 & 20 & $1.2 \%$ & $0.37[0.01,9.72]$ & $\leftarrow$ & & & \\
\hline Wipfler et al. 2011 & 1 & 26 & 2 & 22 & $1.9 \%$ & $0.40[0.03,4.74]$ & $\leftarrow$ & & & \\
\hline Zaffagnini et al. 2006 & 7 & 25 & 10 & 25 & $6.6 \%$ & $0.58[0.18,1.91]$ & & & & \\
\hline Total $(95 \% \mathrm{Cl})$ & & 478 & & 494 & $100.0 \%$ & $0.61[0.45,0.83]$ & & & & \\
\hline Total events & 114 & & 162 & & & & & & & \\
\hline $\begin{array}{l}\text { Heterogeneity: } \mathrm{Chi}^{2}= \\
\text { Test for overall effect: }\end{array}$ & $\begin{array}{l}.04, \mathrm{df}= \\
Z=3.20\end{array}$ & $\begin{array}{l}=11(P= \\
(P=0 . C\end{array}$ & $\begin{array}{l}=0.87) ; 1 \\
001)\end{array}$ & $1^{2}=0 \%$ & & & $\begin{array}{ll}1 & 1 \\
0.1 & 0.2\end{array}$ & $\begin{array}{c}0.5 \\
\text { Favours [PT] }\end{array}$ & $1 \frac{1}{2}$ & 5 \\
\hline
\end{tabular}

Figure 3. Meta-analysis of the comparison arthrometer laxity $\geq 3 \mathrm{~mm}$.

\begin{tabular}{|c|c|c|c|c|c|c|c|c|c|c|}
\hline \multirow{2}{*}{$\begin{array}{l}\text { Study or Subgroup } \\
\text { Aglietti et al. } 2004\end{array}$} & \multirow{2}{*}{$\begin{array}{r}\text { PT } \\
\text { Events } \\
0\end{array}$} & \multirow{2}{*}{$\begin{array}{r}\text { Total } \\
60\end{array}$} & \multirow{2}{*}{$\begin{array}{r}\text { HT } \\
\text { Events } \\
0\end{array}$} & \multirow{2}{*}{$\frac{\text { Total }}{60}$} & \multirow{2}{*}{ Weight } & \multirow{2}{*}{$\begin{array}{l}\text { Odds Ratio } \\
\text { M-H, Fixed, } 95 \% \mathrm{Cl} \\
\text { Not estimable }\end{array}$} & \multicolumn{4}{|c|}{$\begin{array}{c}\text { Odds Ratio } \\
\text { M-H, Fixed, } 95 \% \mathrm{Cl}\end{array}$} \\
\hline & & & & & & & & & & \\
\hline Aune et al. 2001 & 1 & 35 & 2 & 37 & $3.4 \%$ & $0.51[0.04,5.94]$ & & & & \\
\hline Barenius et al. 2010 & 2 & 78 & 2 & 75 & $3.5 \%$ & $0.96[0.13,7.00]$ & & & & \\
\hline Drogset et al. 2009 & 1 & 58 & 1 & 57 & $1.8 \%$ & $0.98[0.06,16.10]$ & & & & \\
\hline Gifstad et al. 2013 & 2 & 41 & 3 & 36 & $5.4 \%$ & $0.56[0.09,3.58]$ & & & & \\
\hline Harilainen et al. 2006 & 0 & 37 & 4 & 37 & $7.9 \%$ & $0.10[0.01,1.91]$ & & & & \\
\hline Holm et al. 2010 & 3 & 28 & 3 & 29 & $4.7 \%$ & $1.04[0.19,5.65]$ & & & & \\
\hline Ibrahim et al. 2005 & 0 & 40 & 0 & 45 & & Not estimable & & & & \\
\hline Laxdal et al. 2005 & 1 & 40 & 2 & 39 & $3.5 \%$ & $0.47[0.04,5.45]$ & & & & \\
\hline Maletis et al. 2007 & 0 & 46 & 1 & 53 & $2.5 \%$ & $0.38[0.01,9.47]$ & & & & \\
\hline Mohtadi et al. 2015 & 19 & 102 & 29 & 104 & $41.7 \%$ & $0.59[0.31,1.14]$ & & & & \\
\hline Sajovic et al. 2018 & 4 & 24 & 2 & 24 & $3.0 \%$ & $2.20[0.36,13.34]$ & & & & \\
\hline Shaieb et al. 2002 & 2 & 33 & 2 & 37 & $3.2 \%$ & $1.13[0.15,8.50]$ & & & & \\
\hline Taylor et al. 2009 & 3 & 42 & 5 & 29 & $9.8 \%$ & $0.37[0.08,1.69]$ & & & - & \\
\hline Webster et al. 2015 & 1 & 17 & 3 & 20 & $4.6 \%$ & $0.35[0.03,3.77]$ & & & & \\
\hline Wipfler et al. 2011 & 3 & 26 & 3 & 22 & $5.1 \%$ & $0.83[0.15,4.58]$ & & & & \\
\hline Total $(95 \% \mathrm{Cl})$ & & 707 & & 704 & $100.0 \%$ & $0.62[0.41,0.95]$ & & & & \\
\hline \multirow{2}{*}{\multicolumn{7}{|c|}{$\begin{array}{l}\text { Heterogeneity: Chi }{ }^{2}=5.31, d f=13(P=0.97) ; I^{2}=0 \% \\
\text { Test for overall effect: } Z=2.20(P=0.03)\end{array}$}} & & & & \\
\hline & & & & & & & 0.01 & $\begin{array}{l}1 \\
0.1 \\
\text { Favours [PT] }\end{array}$ & $\begin{array}{rr}10 & 10 \\
\text { Favours [HT] }\end{array}$ & 100 \\
\hline
\end{tabular}

Figure 4. Meta-analysis of the comparison graft failures.

geneity. All the comparisons were analyzed under a fixed effect model, revealing a consistent result.

Kneeling and anterior knee pain were statistically significant more common in the BPTB group. The morbidity of the harvesting site plays the most important role. Even if improvement in the surgical techniques, post-operative care and rehabilitation programs, these patients reported a higher incidence of kneeling and anterior knee pain (47-50). Furthermore, there can be other several explanations to the higher incidence observed in the BPTB group. From an 
Table II. Overall meta-analysis results.

\begin{tabular}{lcccc}
\hline Outcome & Studies $(\mathbf{n})$ & Samples $(\mathbf{n})$ & Overall Effect \\
\cline { 3 - 5 } & 11 & 1089 & Effect Estimate [95\% CL] & P \\
\hline Pivot-shift test $\geq 3 \mathrm{~mm}$ & 12 & 972 & $0.59[0.43,0.80]$ & 0.0009 \\
\hline Arthrometer laxity $\geq 3 \mathrm{~mm}$ & 8 & 695 & $0.61[0.45,0.83]$ & 0.001 \\
\hline Lachman $\geq 5 \mathrm{~mm}$ & 9 & 734 & $0.54[0.31,0.94]$ & $-0.15[-0.59,0.29]$ \\
\hline Mean arthrometer laxity & 3 & 293 & $0.72[-2.28,3.73]$ & 0.05 \\
\hline IKDC & 4 & 268 & $-2.40[-5.27,0.47]$ & 0.64 \\
\hline Lysholm & 7 & 560 & $1.72[-2.28,3.73]$ & 0.10 \\
\hline Kneeling & 8 & 569 & $2.84[1.75,4.61]$ & $<0.0001$ \\
\hline Anterior knee pain & 16 & 1411 & $0.62[0.41,0.95]$ & 0.03 \\
\hline Graft rupture & & &
\end{tabular}

anatomical point of view, surgery damages the infrapatellar branches of the saphenous nerve, thus possibly creating an alteration of the sensitive paths $(50,51)$. The bone defect induced by BPTB harvesting in the patella and the tibial tubercle can lead to increased pain during kneeling over a surface or during quadriceps contraction (52). Furthermore, has been observed that during a BPTP procedure, there may be a higher risk of implanting the graft under excessive tension, thus increasing the joint pressure (53).

In a normal knee, the endurance of the graft fixation depends on the quality of the bone, type of graft and type of fixation, tunnel position, rehabilitation's program $(54,55)$. A statistically significant higher rate of graft ruptures was evidenced in the 4HST. The analysis of this outcome provided good weights distribution and poor data dispersion. The level of heterogeneity was acceptable and the result is reliable.

The analyzed clinical scores, the Lysohlm and IKDC, reported no consistent results. These comparisons are statistically not significant and affected by high level of heterogeneity and data dispersion. Furthermore, the results are not clinically relevant, since the differences between BPTB and 4SHT are negligible.

The lack of a deep analysis of failures represent the most important limitation of this study. Only graft ruptures were analyzed, but abnormal laxity, patient perception of instability, and pain and stiffness in the operated knee $(56,57)$

\section{REFERENCES}

1. Micheli LJ MJ, Di Canzio J, Zurakowski D. Anterior cruciate ligament reconstructive surgery in adolescent soccer and basketball players. Clin J Sport Med. 1999;9(3):138-141.

2. Hootman JM DR, Agel J. Epidemiology of collegiate injuries for 15 sports: summary and recommendations for injury prevention initiatives. J Athl Train. 2007;42 (2): 311-319. are important outcomes to evaluate. Further studies should provide long-term follow-up and blinded randomized clinical trials to increase the value of the findings. A strength of this meta-analysis is the baseline comparability and the comprehensive nature of this study, along with the strictly eligibility criteria. This is very important to reduce the level of heterogeneity and obtain more reliable results. Another strength of this work is the choice to include only level I and II clinical trials, thus sensibility reducing the risk of publication's bias and providing high scientific evidence.

\section{CONCLUSIONS}

The main findings of this meta-analysis are that BPTP provides more joint stability and reduced the rate of graft rupture but exposes the patients to an increased risk of developing kneeling and anterior knee pain. Giving the greater stability observed in the BPTB group on the one side and the lower incidence of graft rupture, kneeling and anterior knee pain of 4SHT the graft, the recommend the individual selection of the graft for every patient.

\section{CONFLICT OF INTERESTS}

The authors declare that there are no conflict of interests.

3. Hernandez L MW, Amy E. Rehabilitation update for the anterior cruciate ligament injured patient: Current concepts. Boletin de la Asociacion Medica de Puerto Rico. 2006;98(1):62-72.

4. Hewett TE MG, Ford KR. Anterior cruciate ligament injuries in female athletes: Part 1, mechanisms and risk facotrs. American Journal of Sports Medicine. 2006;34(2):299-311. 
5. Hernandez L MW, Amy E. Rehabilitation update for the anterior cruciate ligament injured patient: Current concepts. Boletin de la Asociacion Medica de Puerto Rico 2006;98(1):62-72.

6. Crawford R WG, Bridgman S. Magnetic resonance imaging versus arthroscopy in the diagnosis of knee pathology, concentrating on meniscal lesions and ACL tears: A systematic review. British Medical Bulletin 2007;84:5-23.

7. Lohmander LS OA, Englund M, Roos H. High prevalence of knee osteo- arthritis, pain, and functional limitations in female soccer players twelve years after anterior cruciate ligament injury. Arthritis Rheum. 2004;50(10):3145-3152.

8. Lohmander LS EP, Dahl LL, Roos EM. The long-term consequence of ante- rior cruciate ligament and meniscus injuries: osteoarthritis. Am J Sports Med. 2007;35(10):1756-1769.

9. Spindler KP WR. Clinical practice. Anterior cruciate ligament tear. New England Journal of Medicine. 2008;359(20):135-42.

10. Thorstensson CA LL, Frobell RB, Roos EM, Gooberman-Hill R. Choosing surgery: patients' preferences within a trial of treatments for anterior cruciate ligament injury. A qualitative study. BMC Musculoskeletal Disorders 2009;10:100.

11. Rodriguez-Merchan EC. Evidence-Based ACL Reconstruction. Arch Bone Jt Surg. 2015;3:9-12.

12. Aglietti P, Giron F, Buzzi R, Biddau F, Sasso F. Anterior cruciate ligament reconstruction: bone-patellar tendon-bone compared with double semitendinosus and gracilis tendon grafts. A prospective, randomized clinical trial. I Bone Joint Surg Am. 2004;86-A:2143-2155.

13. Barenius B, Nordlander M, Ponzer S, Tidermark J, Eriksson K. Quality of life and clinical outcome after anterior cruciate ligament reconstruction using patellar tendon graft or quadrupled semitendinosus graft: an 8-year follow-up of a randomized controlled trial. Am J Sports Med. 2010;38:1533-1541.

14. Drogset JO, Strand T, Uppheim G, Odegard B, Boe A, Grontvedt T. Autologous patellar tendon and quadrupled hamstring grafts in anterior cruciate ligament reconstruction: a prospective randomized multicenter review of different fixation methods. Knee Surg Sports Traumatol Arthrosc. 2010;18:1085-1093.

15. Gifstad T, Sole A, Strand T, Uppheim G, Grontvedt T, Drogset JO. Long-term follow-up of patellar tendon grafts or hamstring tendon grafts in endoscopic ACL reconstructions. Knee Surg Sports Traumatol Artbrosc. 2013;21:576-583.

16. Sajovic M, Stropnik D, Skaza K. Long-term Comparison of Semitendinosus and Gracilis Tendon Versus Patellar Tendon Autografts for Anterior Cruciate Ligament Reconstruction: A 17-Year Follow-up of a Randomized Controlled Trial. Am J Sports Med. 2018;46:1800-1808.

17. Webster KE, Feller JA, Hartnett N, Leigh WB, Richmond AK. Comparison of Patellar Tendon and Hamstring Tendon Anterior Cruciate Ligament Reconstruction: A 15-Year Follow-up of a Randomized Controlled Trial. Am J Sports Med. 2016;44:83-90.

18. Leitgeb J, Kottstorfer J, Schuster R, Kovar FM, Platzer P, Aldrian S. Primary anterior cruciate ligament reconstruction in athletes: a 5-year follow up comparing patellar tendon versus hamstring tendon autograft. Wien Klin Wochenschr. 2014;126:397-402.

19. Rahr-Wagner L, Thillemann TM, Pedersen AB, Lind M. Comparison of hamstring tendon and patellar tendon grafts in anterior cruciate ligament reconstruction in a nationwide population-based cohort study: results from the danish registry of knee ligament reconstruction. Am J Sports Med. 2014;42:278-284.

20. Sadoghi P, Muller PE, Jansson V, van Griensven M, Krop$\mathrm{fl} \mathrm{A}$, Fischmeister MF. Reconstruction of the anterior cruciate ligament: a clinical comparison of bone-patellar tendonbone single bundle versus semitendinosus and gracilis double bundle technique. Int Orthop. 2011;35:127-133.

21. Zaffagnini S, Marcacci M, Lo Presti M, Giordano G, Iacono F, Neri MP. Prospective and randomized evaluation of ACL reconstruction with three techniques: a clinical and radiographic evaluation at 5 years follow-up. Knee Surg Sports Traumatol Artbrosc. 2006;14:1060-1069.

22. Moher D LA TJ AD. Preferred reporting items for systematic reviews and meta-analyses: the PRISMA Statement. Open Med. . 2009;3:e123-130.

23. Howick J CI, Glasziou P, Greenhalgh T, Carl Heneghan, Liberati A, Moschetti I, Phillips B, Thornton H, Goddard O, Hodgkinson M. The 2011 Oxford CEBM Levels of Evidence. Oxford Centre for Evidence-Based Medicine. Available at https://www.cebm.net/index.aspx?o=5653. 2011.

24. Padulo J, Oliva F, Frizziero A, Maffulli N. Muscles, Ligaments and Tendons Journal - Basic principles and recommendations in clinical and field Science Research: 2016 Update. Muscles Ligaments Tendons J. 2016;6(1):1-5.

25. Aune AK, Holm I, Risberg MA, Jensen HK, Steen H. Fourstrand hamstring tendon autograft compared with patellar tendon-bone autograft for anterior cruciate ligament reconstruction. A randomized study with two-year follow-up. Am J Sports Med. 2001;29(6):722-8.

26. Beynnon BD, Johnson RJ, Fleming BC, Kannus P, Kaplan M, Samani J, et al. Anterior cruciate ligament replacement: comparison of bone-patellar tendon-bone grafts with two-strand hamstring grafts. A prospective, randomized study. J Bone Joint Surg Am. 2002;84-A(9):1503-13.

27. Feller JA, Webster KE, Gavin B. Early post-operative morbidity following anterior cruciate ligament reconstruction: patellar tendon versus hamstring graft. Knee Surg Sports Traumatol Arthrosc. 2001;9(5):260-6.

28. Harilainen A, Linko E, Sandelin J. Randomized prospective study of ACL reconstruction with interference screw fixation in patellar tendon autografts versus femoral metal plate suspension and tibial post fixation in hamstring tendon autografts: 5-year clinical and radiological follow-up results. Knee Surg Sports Traumatol Arthrosc. 2006;14(6):517-28.

29. Holm I, Oiestad BE, Risberg MA, Aune AK. No difference in knee function or prevalence of osteoarthritis after reconstruction of the anterior cruciate ligament with 4-strand hamstring autograft versus patellar tendon-bone autograft: a randomized study with 10-year follow-up. Am J Sports Med. 2010;38(3):448-54.

30. Ibrahim SA, Al-Kussary IM, Al-Misfer AR, Al-Mutairi HQ, Ghafar SA, El Noor TA. Clinical evaluation of arthroscopically assisted anterior cruciate ligament reconstruction: patellar tendon versus gracilis and semitendinosus autograft. Arthroscopy. 2005;21(4):412-7.

31. Laxdal G, Kartus J, Hansson L, Heidvall M, Ejerhed L, Karlsson J. A prospective randomized comparison of bone-patellar tendon-bone and hamstring grafts for anterior cruciate ligament reconstruction. Arthroscopy. 2005;21(1):34-42.

32. Maletis GB, Cameron SL, Tengan JJ, Burchette RJ. A prospective randomized study of anterior cruciate ligament reconstruc- 
tion: a comparison of patellar tendon and quadruple-strand semitendinosus/gracilis tendons fixed with bioabsorbable interference screws. Am J Sports Med. 2007;35(3):384-94.

33. Mohtadi N, Chan D, Barber R, Oddone Paolucci E. A Randomized Clinical Trial Comparing Patellar Tendon, Hamstring Tendon, and Double-Bundle ACL Reconstructions: Patient-Reported and Clinical Outcomes at a Minimal 2-Year Follow-up. Clin J Sport Med. 2015;25(4):321-31.

34. Razi M, Sarzaeem MM, Kazemian GH, Najafi F, Najafi MA. Reconstruction of the anterior cruciate ligament: a comparison between bone-patellar tendon-bone grafts and fourstrand hamstring grafts. Med J Islam Repub Iran. 2014;28:134.

35. Sajovic M, Vengust V, Komadina R, Tavcar R, Skaza K. A prospective, randomized comparison of semitendinosus and gracilis tendon versus patellar tendon autografts for anterior cruciate ligament reconstruction: five-year follow-up. Am J Sports Med. 2006;34(12):1933-40.

36. Taylor DC, DeBerardino TM, Nelson BJ, Duffey M, Tenuta J, Stoneman PD, et al. Patellar tendon versus hamstring tendon autografts for anterior cruciate ligament reconstruction: a randomized controlled trial using similar femoral and tibial fixation methods. Am J Sports Med. 2009;37(10):1946-57.

37. Wipfler B, Donner S, Zechmann CM, Springer J, Siebold $\mathrm{R}$, Paessler HH. Anterior cruciate ligament reconstruction using patellar tendon versus hamstring tendon: a prospective comparative study with 9-year follow-up. Arthroscopy. 2011;27(5):653-65.

38. Thorlund JB, Creaby MW, Wrigley TV, Metcalf BR, Bennell KL. Knee joint laxity and passive stiffness in meniscectomized patients compared with healthy controls. Knee. 2014;21(5):886-90.

39. Dejour H, Walch G, Deschamps G, Chambat P. Arthrosis of the knee in chronic anterior laxity. Orthop Traumatol Surg Res. 2014;100(1):49-58.

40. Miyazaki T, Uchida K, Sato M, Watanabe S, Yoshida A, Wada $M$, et al. Knee laxity after staircase exercise predicts radiographic disease progression in medial compartment knee osteoarthritis. Arthritis Rheum. 2012;64(12):3908-16.

41. Arnold MP, Lie DT, Verdonschot N, de Graaf R, Amis AA, van Kampen A. The remains of anterior cruciate ligament graft tension after cyclic knee motion. Am J Sports Med. 2005;33(4):536-42.

42. Fleming BC, Abate JA, Peura GD, Beynnon BD. The relationship between graft tensioning and the anterior-posterior laxity in the anterior cruciate ligament reconstructed goat knee. $J$ Orthop Res. 2001;19(5):841-4.

43. Nicholas SJ, D'Amato MJ, Mullaney MJ, Tyler TF, Kolstad $\mathrm{K}, \mathrm{McHugh}$ MP. A prospectively randomized double-blind study on the effect of initial graft tension on knee stability after anterior cruciate ligament reconstruction. Am J Sports Med. 2004;32(8):1881-6.
44. Wiertsema SH, van Hooff HJ, Migchelsen LA, Steultjens MP. Reliability of the KT1000 arthrometer and the Lachman test in patients with an ACL rupture. Knee. 2008;15(2):107-10.

45. Boyer P, Djian P, Christel P, Paoletti X, Degeorges R. [Reliability of the KT-1000 arthrometer (Medmetric) for measuring anterior knee laxity: comparison with Telos in 147 knees]. Rev Chir Orthop Reparatrice Appar Mot. 2004;90(8):757-64.

46. Berry J, Kramer K, Binkley J, Binkley GA, Stratford P, Hunter S, et al. Error estimates in novice and expert raters for the KT-1000 arthrometer. J Orthop Sports Phys Ther. 1999:29(1):49-55.

47. Tsuda E, Okamura Y, Ishibashi Y, Otsuka H, Toh S. Techniques for reducing anterior knee symptoms after anterior cruciate ligament reconstruction using a bone-patellar tendonbone autograft. Am J Sports Med. 2001;29(4):450-6.

48. Jarvela T, Paakkala T, Kannus P, Jarvinen M. The incidence of patellofemoral osteoarthritis and associated findings 7 years after anterior cruciate ligament reconstruction with a bone-patellar tendon-bone autograft. Am J Sports Med. 2001;29(1):18-24.

49. Shelbourne KD, Trumper RV. Preventing anterior knee pain after anterior cruciate ligament reconstruction. Am J Sports Med. 1997;25(1):41-7.

50. Kartus J, Movin T, Karlsson J. Donor-site morbidity and anterior knee problems after anterior cruciate ligament reconstruction using autografts. Arthroscopy. 2001;17(9):971-80.

51. Kartus J, Ejerhed L, Sernert N, Brandsson S, Karlsson J. Comparison of traditional and subcutaneous patellar tendon harvest. A prospective study of donor site-related problems after anterior cruciate ligament reconstruction using different graft harvesting techniques. Am J Sports Med. 2000;28(3):328-35.

52. Victor J, Bellemans J, Witvrouw E, Govaers K, Fabry G. Graft selection in anterior cruciate ligament reconstruction--prospective analysis of patellar tendon autografts compared with allografts. Int Orthop. 1997;21(2):93-7.

53. Arneja S, McConkey MO, Mulpuri K, Chin P, Gilbart MK, Regan WD, et al. Graft tensioning in anterior cruciate ligament reconstruction: a systematic review of randomized controlled trials. Arthroscopy. 2009;25(2):200-7.

54. Xie X, Liu X, Chen Z, Yu Y, Peng S, Li Q. A meta-analysis of bone-patellar tendon-bone autograft versus four-strand hamstring tendon autograft for anterior cruciate ligament reconstruction. Knee. 2015;22(2):100-10.

55. Samitier G, Marcano AI, Alentorn-Geli E, Cugat R, Farmer KW, Moser MW. Failure of Anterior Cruciate Ligament Reconstruction. Arch Bone Jt Surg. 2015;3(4):220-40.

56. Johnson DL, Fu FH. Anterior cruciate ligament reconstruction: why do failures occur? Instr Course Lect. 1995;44:391-406.

57. Kamath GV, Redfern JC, Greis PE, Burks RT. Revision anterior cruciate ligament reconstruction. Am J Sports Med. 2011:39(1):199-217. 